\title{
Development of a Design Skill Assessment Tool
}

\author{
Brian Frank, David S. Strong \\ Queen's University \\ E-mail: \{brian.frank@queensu.ca, strongd@queensu.ca\}
}

\begin{abstract}
This paper presents the results of a three year study on a design skill assessment tool appropriate for elementary, secondary, and university students. In the study students were provided open-ended engineering scenarios and asked to outline the process they would follow to solve the problem. The scenarios were administered before and after design experiences in several settings including enrichment activities with elementary and secondary school students, and university students in first and third year design courses. The scenarios were assessed using an analytic rubric for both design process and tools. The paper reports changes in scores on the surveys pre-and post-activity and differences among groups. Correlation of scores with other measures of design performance are also discussed.
\end{abstract}

\section{Introduction}

Design process cognition assessment is a critical but challenging area of research in engineering education. Authentic design activity generally occurs in a team environment under greatly varying circumstances in industrial settings, and universitylevel projects created to emulate these experiences are generally significantly smaller-scale and timecompressed. Assessment of design activity in even these simplified projects is still a complex undertaking, as student performance in design is a function of factors including design process cognition, disciplines-specific knowledge and skills, team skills, communication skills, project management skills, project complexity, etc.

This study, as originally proposed, was designed to answer some basic questions:

How does design process cognition differ among elementary, secondary, and university students, and how does their understanding change as a result of design activity?

What is the relationship between design process cognition as assessed using a paper-based scenario, and performance on a team-based design project?
In previous years the ability to apply design process to a scenario was observed to improve with age and prior instruction. In this work, the reference to use of tools was also assessed.

Some relevant previous work includes:

- using audio and video recordings of students doing design activities [1,2]

- using a computer-based simulation of a design activity [3]

- asking students to rank, from a provided list, the types of information they would gather to complete the design of a playground [4]

- Closed-ended questionnaire that required students to identify strengths and weaknesses of a proposed process, and to explain rationale for the decision [5]. The results were scored using an analytical rubric which allowed the instructor the ability to identify areas of misunderstanding.

This paper presents the development of an openended survey to assess students' ability to apply design process simple design problems It can be delivered to large number of students in a relatively small period of time, and used to assess development of design ability over the term of a design course. The activity and scoring are quite simple, allowing the tool to be given by instructors and scored relatively quickly by non-experts in design. The tool assesses only the process used for design, as past work has shown this to be correlated with in successful design [6].

In the previous work by the authors a survey instrument and assessment rubric were developed to assess student design skill cognition [7],[8]. This paper presents a revised rubric that was used to assess process and tools, and comparison across multiple years.

\section{Study implementation}

In this work a paper-based design skill assessment (DSA) instrument was designed that required students to describe how they would design a 
process, system, or product to solve some problem presented in a scenario. This scenario was important to ensure that students' design process cognition was assessed in the context of an engineering activity.

The scenarios and instructions were the same as used in the 2008-2009 academic year at Queen's University (Frank, 2009). The final form of the DSA included instructions and a list of three scenarios. The instructions provided to the students were as follows:

\section{Situation:}

You are leading a team of engineers on a design project, and need to plan out how you would approach a problem.

\section{Instructions:}

1) Select and circle one scenario from the box below.

2) Outline, on the back of this page, the specific steps you would take to ensure a successful design for your selected scenario. Please ensure you:

- Outline all special considerations and specific requirements associated with your selected scenario.

- $\quad$ Outline the design process you would follow to solve the problem, listing specific steps your team would take. You do not need to create a specific design, sketch, etc.

The students selected one scenario from a list of three provided on each survey. The scenarios were all open-ended problems, were as follows: design of a pre-schooler tricycle, a desk for vision impaired, payphone, water catchment tank, residence for the school for the deaf, waterfront trail, airplane child seat, food composter, swim goggles, playground structure, helmet, and shopping cart.

\section{$2.1 \quad$ Rubric}

An analytic rubric was created iteratively to assess student responses by typical design steps. Initial versions of the rubric were used to assess a small group of student responses, then modified to improve ease of use and reduce inter-grader variation. The final rubric used for evaluation is shown at the end of the paper.

In the rubric, student responses are evaluated against 6 commonly accepted stages of engineering design: problem definition, preliminary design, conceptual design, detailed design, validation, and implementation. They are also assessed for the overall process (iteration and appropriate order) and use of design tools.

The rubric used in the previous year lumped tools into a single category [8]; in this rubric tools are broken out into usage appropriate to problem definition, conceptual design, preliminary design, and detailed design. The scores on each dimension were rated out of 6 in this administration, rather than 3 as in the previous year, to provide more flexibility. A subtotal, consisting of the sum of scores for problem definition, conceptual design, preliminary design, detailed design, implementation, and validation (categories with white background in the rubric), was computed for comparison. A total score, summing all categories in the rubric, was also computed.

\subsection{Design skill assessment administration}

The DSA was administered to five different groups of students before ("pre") and after ("post") a design activity or course. One groups was students in outreach activities. Two university-level design courses at Queen's University were involved in this study. One is a common first year course of 650 students, APSC-100-Practical Engineering Modules, built around an open-ended team-based design project designed to foster curiosity and an appreciation for the open-ended nature of engineering. It has two deliveries, a fall term delivery for approximately half of the first year class, and a winter term delivery for the other half. The scores in the fall term delivery are designated F100, and the winter term scores are designated W100. The second course, APSC-381-Fundamentals of Design Engineering, is an elective third year multidisciplinary course of 100 students in design methodology, tools, and practice, with significant instructional content and concurrent team design project [8].

In the two university-level engineering courses involved in this study, students were assessed on their course-related design performance projects by teaching assistants and faculty.

In previous years the completion of the survey had no impact on the student's course grade; as a result some students put very little effort into the post-course assessment that was delivered at the very end of the school year. In this implementation, a small portion of the course grade was assigned to "effort" in completing this survey. 


\section{Assessment analysis and results}

A total of 8 people were used to assess the student responses in the 2009-2010 academic year; two course instructors and six engineering summer students. A small group of papers was assessed by all graders to establish a reference for grading style. After discussion and agreement about use of the rubric, six of the graders marked 50-100 papers. The total number of surveys assessed for this study is shown below in Table 1.

Table 1: Number of DSAs scored for each study group.

\begin{tabular}{|l|c|}
\hline \multicolumn{1}{|c|}{ Group } & Number \\
\hline Outreach & 28 \\
\hline First year design course (APSC100) & 240 \\
\hline Third year design course (APSC381) & 66 \\
\hline Total & $\mathbf{3 4 3}$ \\
\hline
\end{tabular}

\subsection{Pre-post comparisons}

Figure 1 shows the distribution of "pre" and "post" subtotal scores on the for the groups of interest. The largest gains occur in APSC381, as would be expected since it is an advanced 12-week course on design tools and methodologies. APSC100 students also show significant gains in the two deliveries. Very modest gains are apparent from the outreach group.

Note that the distribution of "post" scores for APSC100 is higher than "pre" scores for APSC-381, possibly due limited design instruction between first year and winter semester of third year.

Figure 2 shows histograms of change in score for each student in APSC-100. These students made gains in conceptual and preliminary design, which include activities like idea generation, planning, comparing potential designs, and early prototype construction. Note that scores changes corresponding to a major tick on the $\mathrm{x}$-axis are grouped with the lower interval.

Figure 3 shows the corresponding data for APSC-381 students. Much larger gains are made in problem definition, conceptual design, preliminary design, and detailed design. This reflects the nature of the course which does not require students to implement their designs. An even more significant increase in score for use of Tools can be seen students were noted to make reference to design tools in the post-course assessment.

The gains in the outreach group were generally not statistically significant.

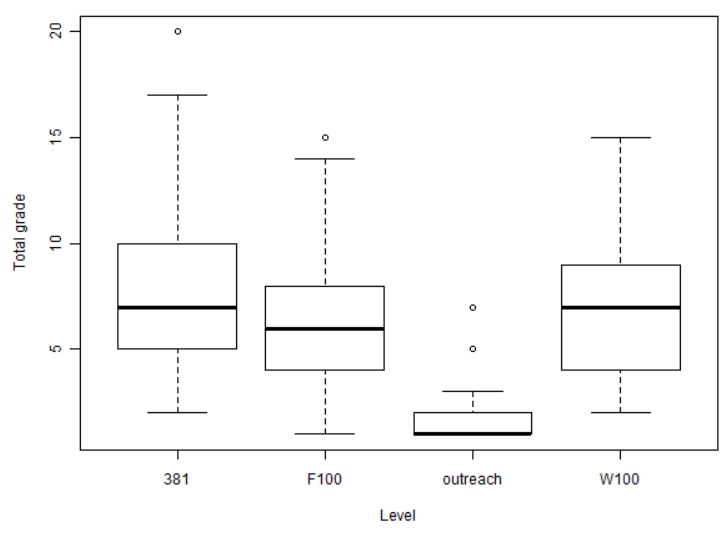

PRE

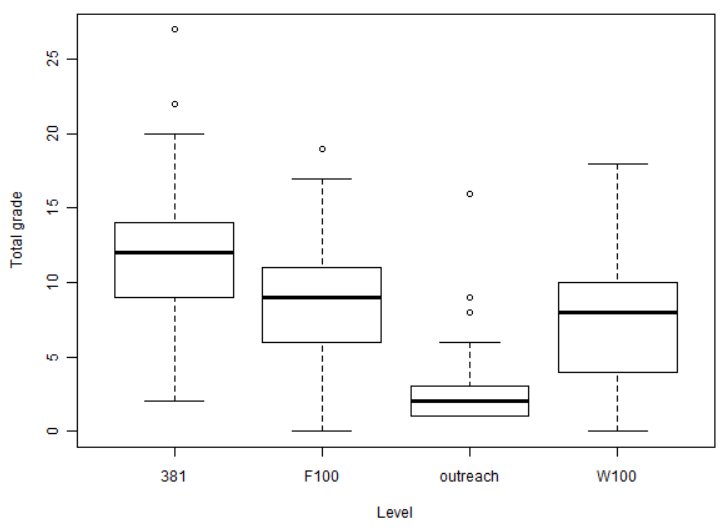

POST

Figure 1: Distribution of scores in 2010 for pre (top) and post (bottom) engineering activity. Boxes show middle quartiles, dark line shows median score. 

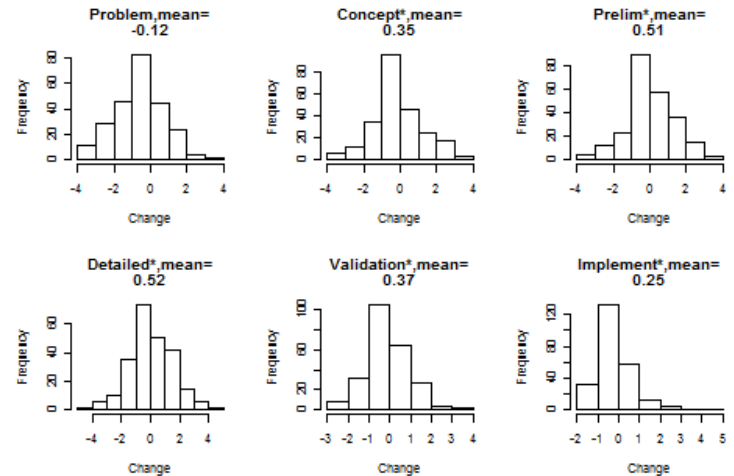

$\underset{0.27}{\text { Tools }^{*} \text {,mean }}=$
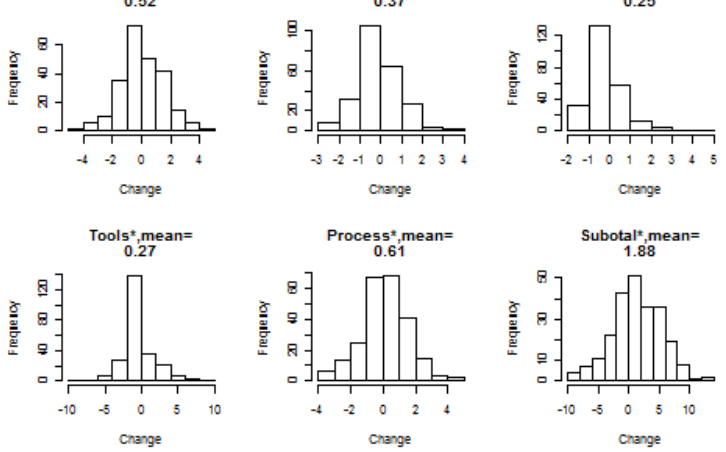

change

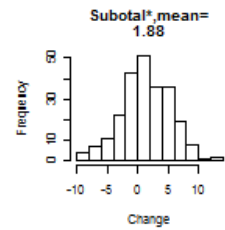

Figure 2: Change in score from in 2010 "pre" to "post" for APSC100 students in the major categories. Statistically significant changes at a $95 \%$ confidence level are indicated with an asterisk.
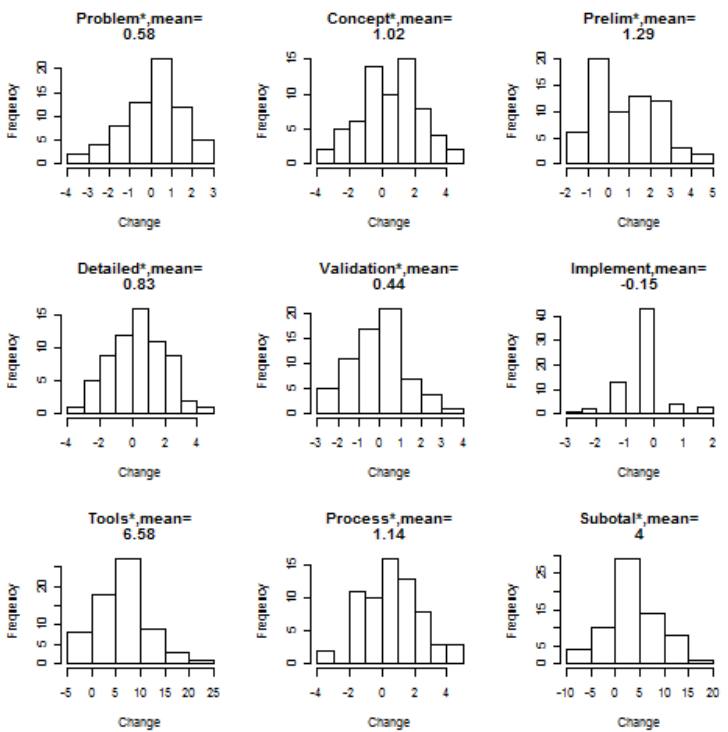

Figure 3: Change in score in 2010 from "pre" to "post" for APSC381 students in the major categories. Statistically significant changes at a $95 \%$ confidence level are indicated with an asterisk.

\subsection{Relationship between course grades and instrument scores}

A relationship between score on the DSA and performance on a design activity would be expected. Since in practice design performance is also a factor of skills including technical discipline skills, team skills, communications, etc., the relationship is complex.

For APSC-381 students the correlation between score total, subtotal, or tools and overall course grade was $<0.1$. The scatter plot is shown in Figure 4 . Compared to previous years there are relatively few students who did well in the course but poorly on this assessment, probably reflecting the assignment of a small percentage of the course mark to effort on this activity. However, the design process understanding is a small portion of the overall grade, so the correlation is understandably small. However, the majority of the scores on the post assessment are reaching the "established" level on the rubric, indicating that students are developing the capacity to apply a process to a scenario.

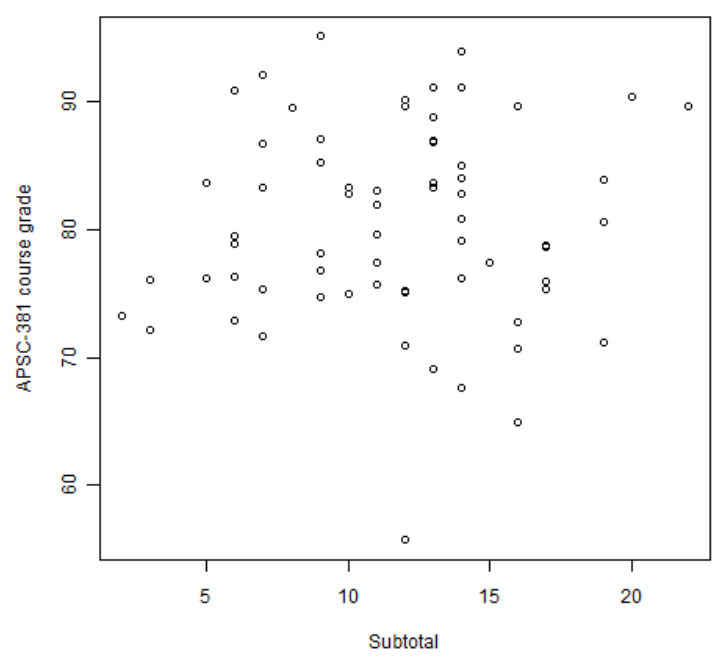

Figure 4: Comparison of subtotal score on the "post" design skill assessment with final course grade in APSC-381. 


\section{Conclusions}

The introduction of a small portion of an overall course grade has improved the student motivation to create a response in line with ability. Separate dimensions on the rubric for tools in the categories of problem definition, preliminary design, conceptual design, and detailed design shows significant improvement in student use of tools over the duration of the third year course, where they are the focus, but little in the first year course where they can be learned by reading but are not taught explicitly.

Learning gains in outreach sessions, where design process instruction is minimal, are not statistically significant. There are learning gains in the first year design course where the idea of using a process is encouraged throughout the duration of the project. Scores distributions of graders were similar to one another, as were distributions of grades by scenario.

After its third year of development the design skills assessment instrument is showing results consistent with the instructional content and application in each course.

\section{Acknowledgements}

The authors would like to acknowledge the work of Mary Spencer, Lauren Bates, Grant Bell, and Sarah Mundell, Adam Kubaki, and Scott Mathewson in scoring the design surveys and providing helpful feedback on the rubric. We would also like to thank our students for volunteering their time and effort to contribute to this study.

\section{References}

[1] C. J. Atman, J.R. Chimka, K.M. Bursic, and H.N. Nachtmann. "A comparison of freshman and senior engineering design processes", Design Studies 20 (2), pp. 131-152, 1999.

[2] Judith E. Sims-Knight, Richard L. Upchurch, and Paul Fortier, "Assessing Students' Knowledge of Design Process in a Design Task", Frontiers in Education, Indianapolis, IN, 2005

[3] Sims-Knight, J. Upchurch, R. Pendergrass, N. Meressi , T. Fortier, P. , "Assessing design by design: progress report 1", Frontiers in Education, 2003, 5-8 Nov. 2003

[4] J. Light, R. Korte, K. Yasuhara, D. Kilgore, "Exploring the relationships among performance on engineering tasks", confidence, gender, and first year persistence, 2007 ASEE Annual General Conference

[5] R. Bailey, Z. Szabo, "Assessing Engineering Design Process Knowledge”, Int. J. Engng Ed. Vol. 22, No. 3, pp. 508-518, 2006
[6] Radcliffe, David F; Lee, Tat Y., "Design methods used by undergraduate engineering students", Design Studies, Vol: 10, Issue: 4, October, 1989, pp. 199-207

[7] B. Frank, D. Strong, Survey-Based Assessment of Design Skill Development in Engineering Project Courses, CDEN 2008, Halifax NS

[8] B. Frank, D. Strong, J. Boudreau, A. Pap, Design Skill Assessment From Pre-University to Third Year, CDEN 2009, Halifax NS 


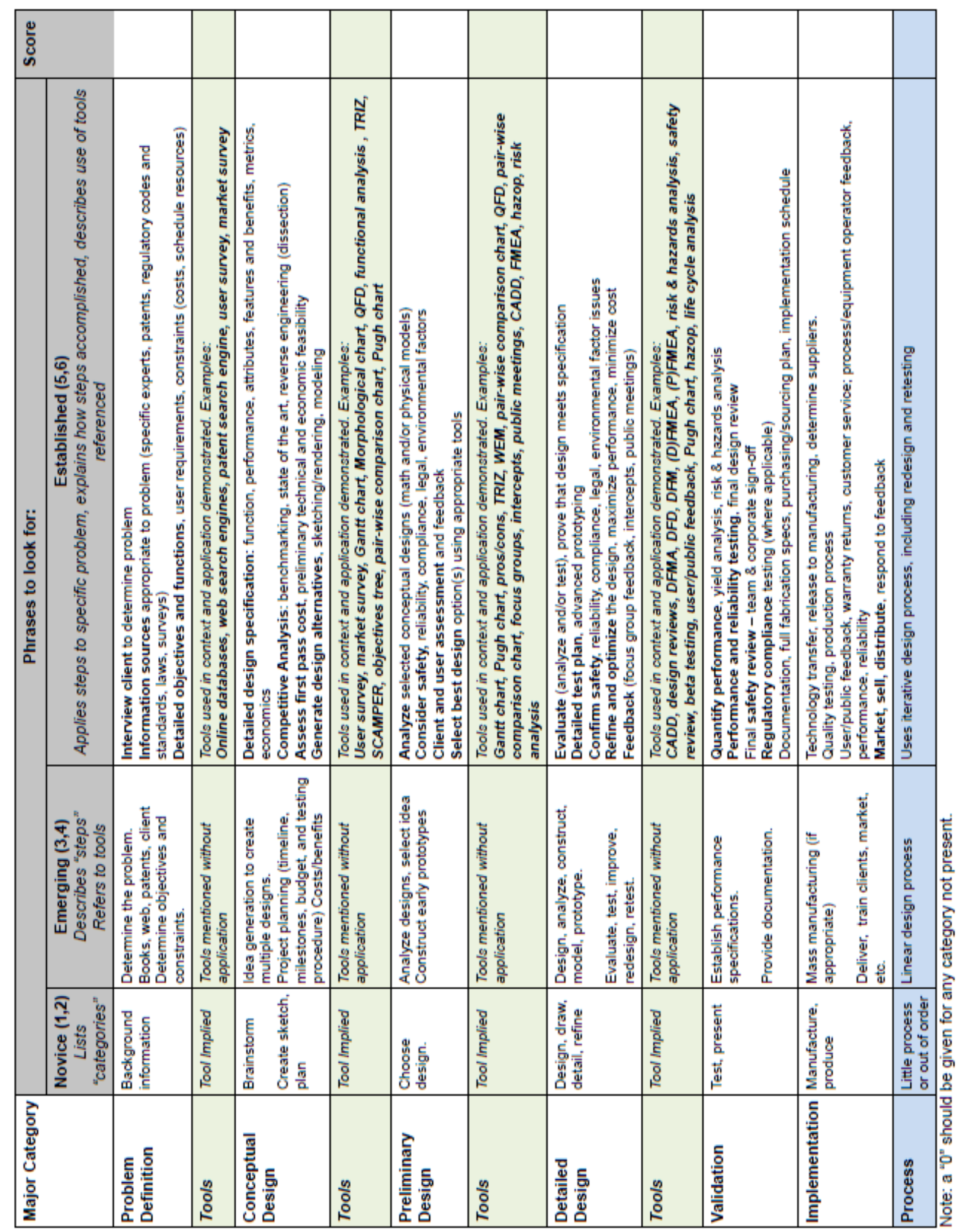

Figure 5: Scoring rubric used to assess design process. 